\title{
Son Preference and Family Limitation in Pakistan: A Parity- and Contraceptive Method-Specific Analysis
}

\begin{abstract}
CONTEXT: Son preference exerts a strong influence over contraceptive and fertility decisions in many South Asian countries. In Pakistan, where fertility remains high and contraceptive use low, research on son preference has been limited.
\end{abstract}

\section{By Melanie Dawn Channon}

Melanie Channon is a research fellow at the Oxford Institute of Population Ageing, University of Oxford, UK.

RESULTS: Parity progression and choice of contraceptive method are increasingly associated with the sex composition of children. Many respondents wanted at least two sons, though most also wanted at least one daughter. Analyses suggest that the prevalence of modern contraceptive use among parous women would have been 19\% higher in 2012-2013 in the absence of son preference. Permanent method use was extremely low among women with no sons and increased significantly with number of sons. The association between number of sons and use of temporary methods was weaker, while son preference had little relationship with traditional method use.

CONCLUSIONS: The association of son preference with parity progression and modern contraceptive use has become stronger in Pakistan. Continuation of the fertility transition may be difficult unless the degrees of differential stopping behavior and differential contraceptive use decline.

International Perspectives on Sexual and Reproductive Health, 2017,43(3):99-110, https://doi.org/10.1363/43e4317

A well-known preference for male rather than female offspring is found in many Asian countries. ${ }^{1}$ Like its South Asian neighbors (e.g., India, Bangladesh and Nepal), Pakistan has a patriarchal social system in which the level of female empowerment is low. Because of the country's patrilineal inheritance system, as well as the large dowry that a woman's family typically pays when she marries and the extremely low level of female labor force participation, daughters are often viewed as posing a heavier economic burden than sons do. ${ }^{2}$ In recent analyses, Pakistanis had much stronger latent preferences for male offspring than did residents of virtually any other country with available data, including India, where preference for sons results in high levels of sex-selective abortion., ${ }^{3,4}$ Evidence from India indicates that son preference can also elevate fertility and depress contraceptive use., ${ }^{5,6}$ Despite these potentially substantial impacts, the extent of son preference in Pakistan has received little attention in recent years, with the exception of a study by Zaidi and Morgan that found no evidence of sex-selective abortion in the country but did find evidence that parity progression is affected by son preference. ${ }^{7}$

Son preference encompasses not only a preference to have more sons than daughters, but also discrimination against daughters once they are born. For example, in Pakistan, women and girls have less access to health and medical services than do their male counterparts. ${ }^{8-10}$ Likewise, in India, girls face discrimination or experience disadvantage in such areas as health and education, and, compared with boys, have higher levels of mortality and are more likely to be victims of feticide or infanticide. ${ }^{11-13}$ In some countries, including China, India and Nepal, the preference for sons combined with declining fertility and increased availability of technology has resulted in prenatal sex selection (sex-selective abortion) and large numbers of "missing" girls. ${ }^{14-16}$ In Pakistan, mortality and morbidity historically have been substantially higher among girls than among boys, and the country received attention in Sen's seminal work on "missing women." 17 Indeed, child mortality rates have been higher among girls than among boys in every Pakistan Demographic and Health Survey (PDHS), and while the gap has narrowed as overall mortality has decreased, it remains evident among children aged 1-4. ${ }^{18,19}$

If it is strong enough, son preference has the potential to produce a range of demographic outcomes through the effects it can have on reproductive decision making. For example, differential stopping behavior is the practice of choosing to stop childbearing when the sex composition of one's family has reached a certain configuration. In the context of South Asia, the desired sex composition generally includes having a minimum number of sons, though recent 
evidence from India suggests that many parents desire at least one daughter in addition to two sons. ${ }^{20,21}$ Setting targets for a minimum number of sons (or daughters) can lead, at the population level, to an increase in fertility (unless prenatal sex determination is widely used) and a reduction in uptake of contraception. At the same time, as ideal family size declines, son-targeting behavior (through both differential stopping and prenatal sex selection) becomes more necessary (a phenomenon known as intensification) for couples who want sons, because the chances of having two sons falls if a couple is willing to have only a limited number of children. ${ }^{22}$ Such behavior distorts the sex ratio by family size, since, on average, girls will be born into larger families and at an earlier parity than will boys. ${ }^{23}$ Children born into larger families and at an earlier parity face disadvantages, such as having to shoulder a disproportionate share of household chores and sibling childcare, which, in a culture of son preference, increases disparities between the early life experience of boys and that of girls.

One of the key Sustainable Development Goals is gender equality, achievement of which will require not only an end to all forms of discrimination against women and girls, including son preference, but also universal access to sexual and reproductive health care. Pakistan continues to have higher rates of fertility and population growth than its South Asian neighbors (bar Afghanistan) and the AsiaPacific region as a whole. While fertility has been decreasing and contraceptive uptake increasing in Pakistan, the rate of change has been relatively slow and the country failed to achieve the majority of the targets set by the United Nations Millennium Development Goals (MDGs). In particular, the goals for target 5B (to provide universal access to reproductive health by 2015) proved wildly optimistic; in 2015, the contraceptive prevalence rate was still well below the target (35\% vs. $55 \%$ ) and the total fertility rate remained well above the target (3.7 vs. 2.1) ${ }^{24}$ Given Pakistan's large population, progress in the country will be important if the goal, set at the 2012 London Summit on Family Planning, of expanding family planning services to an additional 120 million women worldwide is to be achieved..$^{25}$

Because substantive evidence is hard to find, there has been some debate about whether sex ratios at birth in Pakistan are skewed, which would be evidence of sexselective abortion. Although this article does not discuss sex-selective abortion in detail, such abortions are an important element of son preference elsewhere in South Asia. The United Nations estimates that the sex ratio at birth in Pakistan is skewed at 109 boys per 100 girls-well above the expected biological ratio of 105 per 100-and projects that it will remain at this elevated level for years to come. (To put this into context, the estimated ratio is 111 in India and 107 in Nepal. ${ }^{26}$ ) However, it seems unlikely that Pakistan's ratio can be so high at the national level, given that abortion is legally permitted only to save a woman's life or for the purpose of "necessary treatment." ${ }^{27}$ It is important to note that while Pakistan's abortion law is strict, enforcement is limited and the incidence of first-trimester abortions is high in some areas. ${ }^{28-30}$ That said, obtaining a sex-selective abortion is likely to be difficult, because the procedure would need to be performed in the second trimester, before which ultrasound cannot detect the sex of the fetus. A 2015 analysis suggested that the skewed sex ratios observed in earlier data (including PDHS and census data) were the result of widespread underreporting of girls, rather than of a genuinely skewed sex ratio at birth. ${ }^{29}$ Such large-scale underreporting of girls exists in China, where it has led to an overestimate of sex-selective abortion levels, though sex selection is nonetheless clearly common there. ${ }^{31}$ The underreporting of female births further highlights the importance of fully understanding the dynamics of son preference, because in the absence of sex-selective abortion the demographic impact of son preference will take a different trajectory, stalling the transition to lower fertility.

The current study systematically investigates sex preferences in Pakistan by using a variety of methods to look at both reported preferences and the relationship between these preferences and reproductive behavior. Sex preferences for both men and women are analyzed using three rounds of PDHS data. Other analyses examine the relationship of family sex composition with the desire for more children, actual parity progression, contraceptive use and contraceptive method choice. These analyses provide a comprehensive picture of the extent of and changes in sex preferences over time, and of the demographic impact of these preferences.

\section{METHODS}

The data used in these analyses are from Demographic and Health Surveys conducted in Pakistan in 1990-1991, 2006-2007 and 2012-2013. ${ }^{18,32,33}$ These surveys were national, but excluded the Federally Administered Tribal Areas, Azad-Kashmir, and Jammu and Kashmir. The descriptive analyses in this article used data from evermarried men and women aged 15-49, though no data from men were available in the 2006-2007 survey. Multivariate analyses were restricted to women who were parous and not pregnant; some analyses were further limited to women who had completed childbearing at the time of the survey. All analyses used sampling weights.

Son preference was studied by examining the observed sex ratio at last birth and the reported ideal sex composition of children (i.e., the number of boys and girls the respondent ideally would like to have). ${ }^{4}$ The ideal sex composition measure, which was reported by both female and male PDHS respondents, assesses the strength of reported son preference, but it is subject to social desirability bias (sex preferences may be underreported if they are seen as undesirable or taboo) and to rationalization bias (people may report a desire for the sex composition of the children they actually have). The magnitude of these biases may differ among socioeconomic groups; older women will likely be more subject to rationalization bias, while women with higher levels of education may be more influenced by 
social desirability bias. As a result, the actions an individual takes to have sons may not reflect the ideal sex composition he or she reports.

The sex ratio at last birth is a better indicator of the extent to which women and men are trying to have sonsspecifically, through differential stopping behavior-since this measure should not be subject to the same biases as desired sex ratio at birth. Sex ratio at last birth simply refers to the ratio of males to females among children who were their mother's last-born child (i.e., after that birth she had no more children). The sex ratio at last birth will be skewed if childbearing is more likely to cease after a male birth than a female birth. It should be noted, however, that this measure is an aggregate indicator rather than an individual-level one. The conditional sex ratio at birth (the sex ratio at birth according to the number and sex of the mother's previously born children) was also calculated, to look for evidence of a skewed sex ratio dependent on the sex composition of previous births. Because the results were inconsistent and showed no clear evidence of prenatal sex selection, the detailed results are not reported here; interested readers may wish to consult the similar analysis by Zaidi and Morgan, who concluded that PDHS data do not show evidence of sexselective abortion. ${ }^{7}$

Parity-specific logistic regression models were used to look at the association between the sex composition of previous children and the probability of having additional children. Women were included in these models only if they had completed childbearing; they were considered to have done so if they had been sterilized at the time of the survey, or if they said they desired no more children.

The relationship between son preference and contraceptive use was explored using the Arnold method, ${ }^{34}$ which examines contraceptive use by parity and sex composition of previous children. An underlying assumption of this method is that at any given parity, women's contraceptive use should not differ according to the sex composition of previous children; thus, in the absence of sex preference, women would hypothetically use contraceptives to the same degree as the women who were most satisfied with their current sex composition (conceptualized as the subgroup of women at that parity with the highest level of contraceptive use). For example, in the 2012-2013 PDHS, $9 \%$ of women with one daughter and no sons were using modern contraceptives, while $12 \%$ of women with one son and no daughters were doing so. According to the Arnold method, one would assume that in the absence of son preference, $12 \%$ of women with one child would use a modern contraceptive method, regardless of the sex of that child. That is, one assumes that women with fewer sons have artificially low contraceptive use due to their preference for sons. The hypothetical contraceptive use in the absence of sex preference is calculated for women at every parity; the results are then combined to produce an overall estimate of the posited effect of sex preference on contraceptive use. This is a particularly useful descriptive method in that it can take account of any form of sex preference, though it does not adjust for other factors. In the current analysis, this method was used only for women with six or fewer children because sample sizes were too small for higher parities.

To extend the analysis, multinomial models were used to look at the association between son preference and choice of contraceptive method. The dependent variable, method used, had four categories: none, temporary modern method (i.e., any method but sterilization), permanent modern method and traditional method. ${ }^{5}$ Separate models were run by parity; to bolster sample sizes, parities two and three were combined, as were parities four and five Results for women with just one child or more than five children are not shown because they did not yield any statistically significant differences.

Because both parity progression and contraceptive method choice are affected by a wide variety of factors, all multivariate analyses adjusted for women's age, educational attainment (categorized as none, primary, secondary, or higher) and area of residence (urban or rural), as well as for household wealth (classified as quintiles on the basis of household assets). In addition, because child mortality is an important factor in decisions concerning future childbearing, a dummy variable was included to indicate whether any of the respondent's children had died at any point before the conception of the relevant child (i.e., at least nine months before the birth).

Results of the multivariate analyses are presented as predicted probabilities. ${ }^{35,36}$ These probabilities were calculated such that the remaining covariates were held constant at their means (or at the most common answer, in the case of categorical covariates), and thus represent the association between the sex composition of previous children and method choice or parity progression if all else is equal. For ease of comparison, predicted probabilities are displayed graphically with $95 \%$ confidence intervals. In some cases, comparisons of sex composition categories are presented in the text as odds ratios obtained by converting predicted probabilities to odds and then calculating the relevant ratios.

\section{RESULTS}

\section{Desired Sex Composition of Children}

In 2012-2013, the average desired family size in Pakistan was 4.1 children among women and 4.2 among men, virtually unchanged since 1990-1991. However, sex composition preferences shifted over time; for example, among women, the desired sex ratio at birth decreased from 172 in 19901991 to 144 in 2012-2013. In 1990-1991, women who gave a numeric response indicated that, on average, they wanted 2.3 boys and 1.6 girls, whereas in 2012-2013 they wanted 2.1 boys and 1.6 girls.* Comparing the responses from 1990-1991 with those from later years is problematic, however, since more than $60 \%$ of women and men provided a

*The sums of the desired numbers of boys and girls for each year do not match the desired family sizes noted earlier because some women reported desiring children of either sex. 
TABLE 1. Percentage of ever-married women and men aged 15-49 who reported specified ideal sex composition of children, according to survey year, Pakistan Demographic and Health Survey

\begin{tabular}{|c|c|c|c|c|c|}
\hline \multirow[t]{2}{*}{ Sex composition } & \multicolumn{2}{|c|}{ 1990-1991 } & \multirow{2}{*}{$\begin{array}{l}\text { 2006-2007 } \\
\text { Women }\end{array}$} & \multicolumn{2}{|c|}{ 2012-2013 } \\
\hline & Women & Men & & Women & Men \\
\hline \multicolumn{6}{|l|}{ NUMERIC RESPONSES } \\
\hline 1 boy, 1 girl & 4.4 & 3.9 & 11.4 & 12.3 & 8.6 \\
\hline$>1$ boy, 1 girl & 9.3 & 9.0 & 18.0 & 16.6 & 18.2 \\
\hline 2 boys, 2 girls & 13.7 & 11.4 & 30.5 & 32.5 & 24.9 \\
\hline$>2$ boys, 2 girls & 3.8 & 4.4 & 11.7 & 9.7 & 12.5 \\
\hline Other numeric responses ${ }^{*}$ & 6.6 & 4.7 & 18.6 & 24.7 & 28.6 \\
\hline Total & 37.8 & 33.3 & 90.1 & 95.8 & 92.9 \\
\hline \multicolumn{6}{|l|}{ ALL RESPONSES } \\
\hline Equal no. of girls and boys & 19.9 & 16.2 & 46.8 & 51.9 & 40.0 \\
\hline More boys than girls & 15.4 & 16.3 & 35.0 & 30.6 & 36.2 \\
\hline More girls than boys & 1.5 & 0.2 & 3.1 & 2.4 & 3.4 \\
\hline Nonnumeric & 62.2 & 66.7 & 9.9 & 4.2 & 7.1 \\
\hline No sex preference ${ }^{\dagger}$ & 1.2 & 0.6 & 5.2 & 10.9 & 13.2 \\
\hline Total & 100.0 & 100.0 & 100.0 & 100.0 & 100.0 \\
\hline
\end{tabular}

Notes: Percentages may not sum to totals because of rounding. Data from men were unavailable for 2006-2007. *Includes "no sex preference" responses (see below). tRefers to numeric responses in which participants indicated they wanted a particular number of children of "either sex" rather than indicating specific numbers of boys and girls.

TABLE 2. Percentage of parous women and men aged 15-49 who wanted at least one more child, by parity and sex composition of children, according to survey year, Pakistan Demographic and Health Survey

\begin{tabular}{|c|c|c|c|c|c|}
\hline \multirow{2}{*}{$\begin{array}{l}\text { Parity/sex } \\
\text { composition }\end{array}$} & \multicolumn{2}{|c|}{ 1990-1991 } & \multirow{2}{*}{$\begin{array}{l}\text { 2006-2007 } \\
\text { Women }\end{array}$} & \multicolumn{2}{|c|}{ 2012-2013 } \\
\hline & Women & Men & & Women & Men \\
\hline \multicolumn{6}{|l|}{ Parity 1} \\
\hline 0 boys, 1 girl & 81.3 & 82.3 & 86.9 & 90.0 & 94.8 \\
\hline 1 boy, 0 girls & 80.5 & 85.5 & 83.5 & 86.9 & 92.8 \\
\hline \multicolumn{6}{|l|}{ Parity 2} \\
\hline 0 boys, 2 girls & 74.9 & $75.5^{*}$ & 84.6 & 83.5 & 88.1 \\
\hline 1 boy, 1 girl & 61.4 & 60.2 & 58.9 & 62.2 & 75.7 \\
\hline 2 boys, 0 girls & 60.1 & $64.0^{*}$ & 59.7 & 58.8 & 70.1 \\
\hline \multicolumn{6}{|l|}{ Parity 3} \\
\hline 0 boys, 3 girls & 74.0 & $67.4^{*}$ & 77.4 & 74.0 & $80.5^{*}$ \\
\hline 1 boy, 2 girls & 56.9 & 52.4 & 45.7 & 53.1 & 60.0 \\
\hline 2 boys, 1 girl & 34.7 & $44.6^{*}$ & 32.1 & 31.2 & 36.6 \\
\hline 3 boys, 0 girls & 42.4 & $52.4^{*}$ & 35.0 & 37.8 & 62.1 \\
\hline \multicolumn{6}{|l|}{ Parity 4} \\
\hline 0 boys, 4 girls & $65.1^{*}$ & $73.8^{*}$ & 74.7 & 62.1 & $56.0^{*}$ \\
\hline 1 boy, 3 girls & 50.7 & $39.5^{*}$ & 36.9 & 33.1 & 44.8 \\
\hline 2 boys, 2 girls & 25.1 & 27.7 & 16.2 & 18.3 & 21.9 \\
\hline 3 boys, 1 girl & 18.3 & $38.0^{*}$ & 17.2 & 11.6 & 16.4 \\
\hline 4 boys, 0 girls & $32.6^{*}$ & $10.1^{*}$ & 40.8 & 24.2 & $55.4^{*}$ \\
\hline
\end{tabular}

non-numeric response to the question about ideal family size in 1990-1991, compared with only 4-7\% in 2012-2013 (Table 1).* This substantial shift away from non-numeric responses may indicate an increasing preference for limiting family size, even though the reported ideal number of children among respondents who gave a numeric answer did not decline. Individuals who provide non-numeric responses are less likely than peers to see fertility as falling within the "calculus of conscious choice,"37(p.65) and thus have higher fertility and are less likely than other women to use contraceptives. ${ }^{37,38}$ The shift away from such responses is likely to be accompanied by an increase in differential

*Non-numeric responses are those that use words rather than numbers; examples include "don't know" or "up to God/Allah." stopping behavior (because more people are making active, parity-specific decisions about their fertility) and to result in individuals' acting upon latent son preference.

Among survey participants who gave a numeric response, the most commonly desired family composition was two boys and two girls. This was the case in all three surveys and among both women and men. In the full sample of respondents, equal sex composition was the most commonly reported ideal in the last two surveys and was the most common ideal in the first survey among women who gave numeric responses. However, a substantial minority of respondents reported desiring more boys than girls. In 2012-2013, for example, 31\% of women and $36 \%$ of men wanted to have more boys than girls; in comparison, only $2-3 \%$ reported wanting more girls than boys.

While data on ideal sex composition provide important insight into sex preferences, it can be more useful to consider the relationship between these preferences and realized fertility. Table 2 presents the percentage of women and men who said they wanted more children, according to parity and the sex composition of previous children. Although the most common numeric desired family composition was two boys and two girls, both men and women were less likely to want more children if they had three boys and one girl than if they had two of each. In 2012-2013, for example, 12\% of women and 16\% of men who had three boys and one girl said they wanted more children, compared with $18 \%$ of woman and $22 \%$ of men who had two boys and two girls. Generally, at all parities and for all sex compositions of children, men were more likely than women to want another child, especially in 2012-2013. In addition, for the two most recent surveys, at every parity and for both sexes, the desire for another child was highest among those with no sons. This trend was particularly marked at parities 3 and 4; at parity 4 in 2012-2013, for example, 62\% of women with no sons wanted another child, a proportion five times that among women with three sons (12\%). It is also striking that the desire to have another child in the absence of any sons has generally not diminished since 1990-1991. This adds further weight to the evidence that, in Pakistan, a preference for at least four children interacts with the preference for sons. In the most recent survey, $43 \%$ of women and $51 \%$ of men wanted another child after their third, while just $22 \%$ of women and $29 \%$ of men wanted another after their fourth (data not shown).

\section{Sex Ratio at Last Birth}

In contrast to the stability of desired family size over time, the sex ratio at last birth has increased substantially since the first PDHS: In 1990-1991 the ratio was 118, but by 2006-2007 it was 131 and in 2012-2013 it was 128 (not shown). This increase is due largely to the corresponding decrease in fertility (from a total fertility rate of 4.9 in 1990-1991 to 3.8 in 2012-2013). ${ }^{7}$ Figure 1 shows the sex ratio at last birth, by parity, for all three surveys. 
FIGURE 1. Sex ratio at last birth to women aged 15-49 who had stopped childbearing, by parity, according to survey year

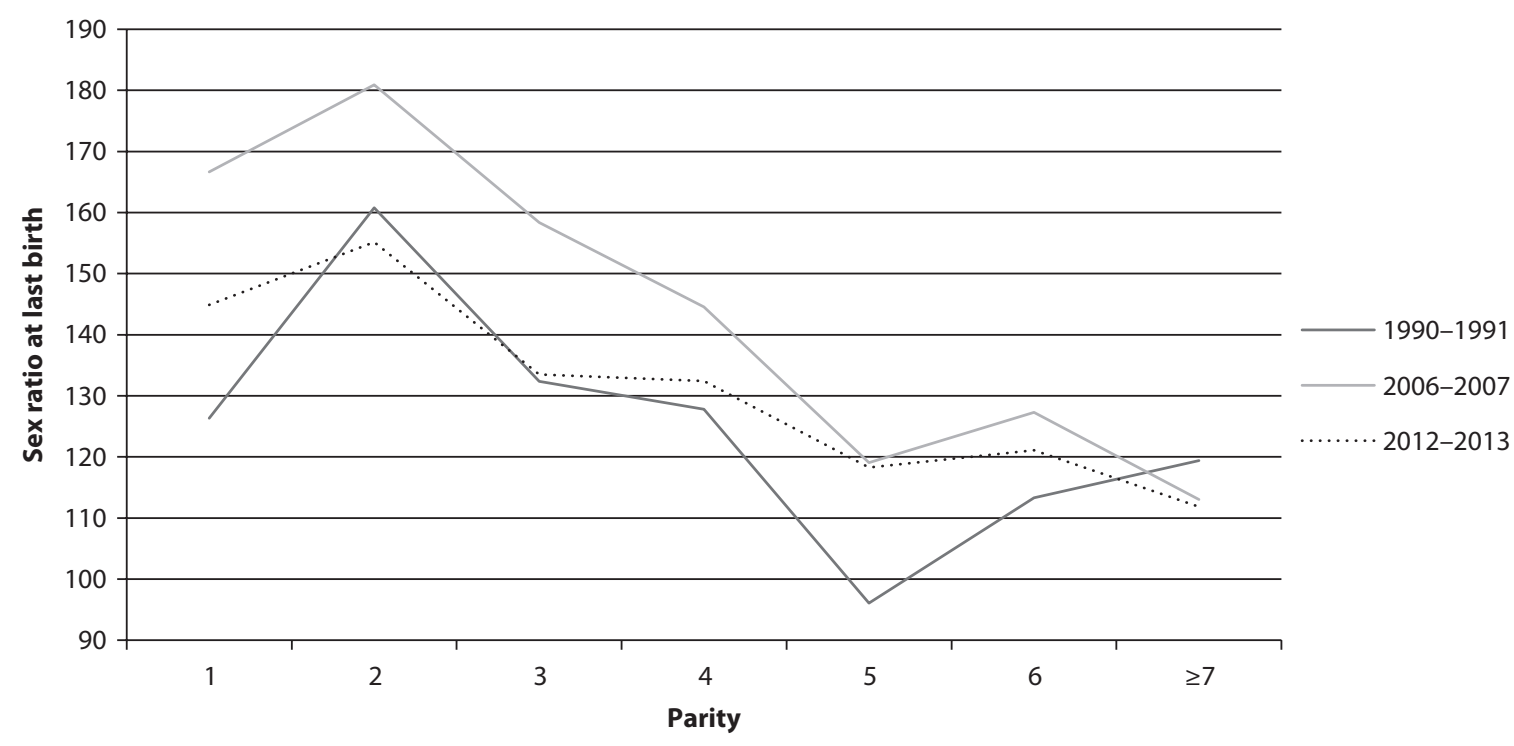

The most recently born child was more likely to be male than female (i.e., the sex ratio was more than 100) at every parity and in every survey (except for parity 5 in 1990-1991). Sex ratios were generally highest for lowerorder births; in all three surveys, women who stopped childbearing after the birth of their second child had the highest sex ratio at last birth (155-180). For higher-order births (especially above parity 4), sex ratios were much closer to the expected ratio of 105 in all surveys, which is not surprising given that in South Asia childbearing decisions are less likely to be made consciously or rationally at higher birth orders than at lower ones. ${ }^{39}$ As fertility has declined, more women have stopped childbearing at an earlier parity, meaning that the overall sex ratio at last birth will tend to increase in the presence of differential stopping behavior. In 1990-1991, just 17\% of women stopped childbearing after having three or fewer children, but the proportion had increased to $22 \%$ by 2006-2007 and 25\% by 2012-2013 (not shown).

\section{Parity Progression}

The logistic regression analyses of parity progression show that the number of sons women had was negatively associated with the probability that they would have more children (Figure 2). The negative association was generally strongest in the most recent survey. However, it was statistically significant only for up to two sons; having additional sons was not associated with further changes in the probability of progression to higher parities.

The results of the parity progression models do not indicate widespread preference for two sons and two daughters. In the most recent survey, the odds of having another child were $74 \%$ lower among women with two sons and two daughters than among those with four daughters but no sons ( $\mathrm{p}<.001$; calculation not shown); similarly, the odds were $77 \%$ lower among women with three sons and one daughter $(\mathrm{p}<.001)$ and $78 \%$ lower among women with four sons and no daughters $(\mathrm{p}<.001)$ relative to women with four daughters and no sons. The probability of parity progression did not differ among women with two, three or four sons. The results from 2006-2007 were generally similar to those from 2012-2013.

The association between sex composition and parity progression was weaker in 1990-1991 than in later surveys, though there appears to have been a slight preference for a balanced sex composition. At parity four, women with two or three sons had 63-69\% lower odds of having another child than did women with no sons $(\mathrm{p}<.05)$, but the likelihood of parity progression did not differ between those with no daughters and those with no sons. At parity 3, women with two sons were less likely than those with no sons to progress to the next parity $(\mathrm{p}<.05)$, but again no difference was evident between those with no sons and those with no daughters. It seems likely that parity progression decisions were less commonly within the calculus of conscious choice at the time of the earliest survey, especially because just $15 \%$ of parous, nonpregnant women were using any method of contraception (not shown).

Overall, the preference for at least two sons was particularly pronounced in the most recent survey. Although reported son preference has decreased over time, it appears that differential stopping behavior has increased.

\section{Contraceptive Use}

Table 3 shows the relationship between son preference and contraceptive use among parous, nonpregnant, evermarried women in all three surveys. Contraceptive use clearly varied substantially according to the sex composition of children, and was generally lowest among women who had borne only daughters, especially in 2012-2013. In that survey, women with only daughters

*Percentages in this section are derived by converting the predicted probabilities from the logistic regression models on which Figure 2 is based to odds and then calculating the relevant odds ratios. 
FIGURE 2. Predicted probabilities (and 95\% confidence intervals) from logistic regression analyses examining the likelihood that women aged 15-49 would progress to next parity, by number of sons already born, according to survey year, Pakistan Demographic and Health Survey

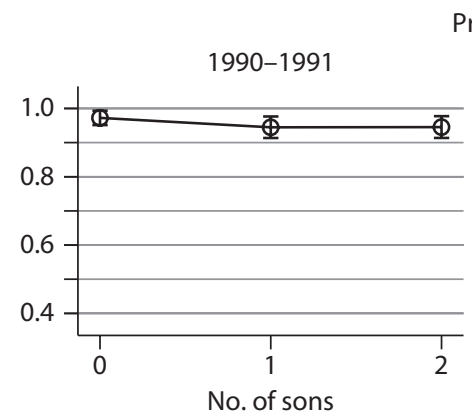

Predicted probability of progressing from parity 2 to 3

2006-2007

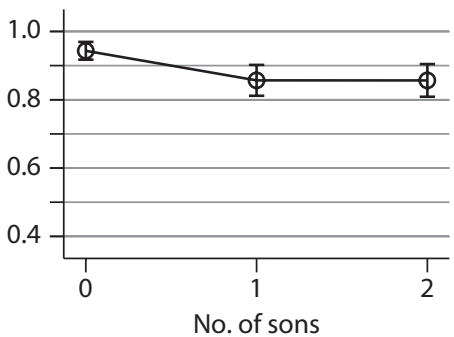

2012-2013

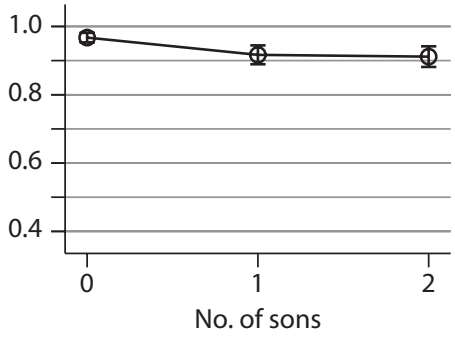

Predicted probability of progressing from parity 3 to 4

1990-1991

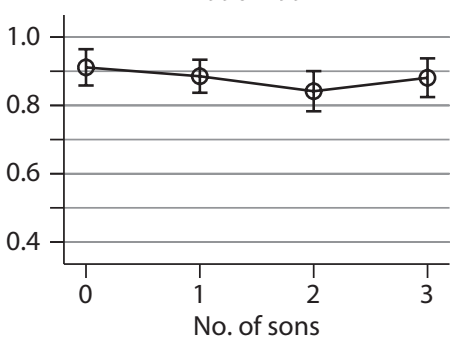

2006-2007

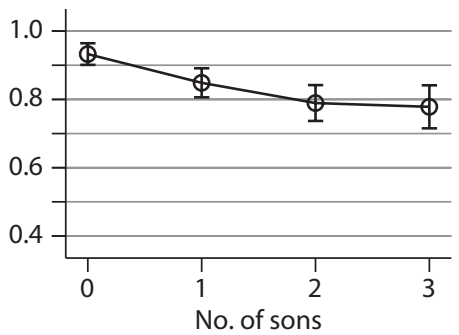

2012-2013

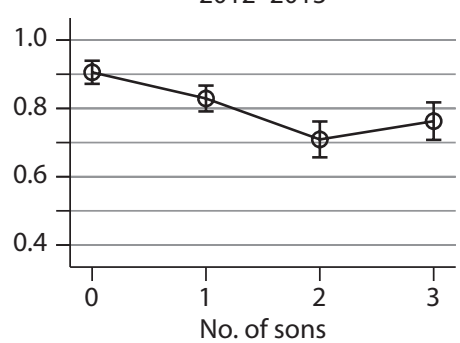

Predicted probability of progressing from parity 4 to 5

1990-1991

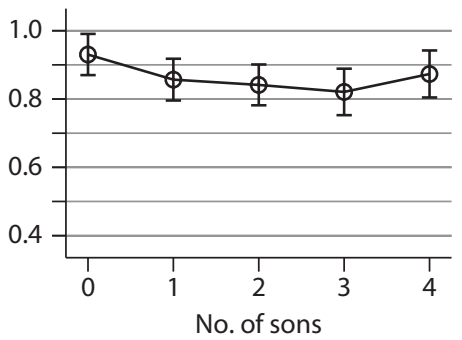

2006-2007

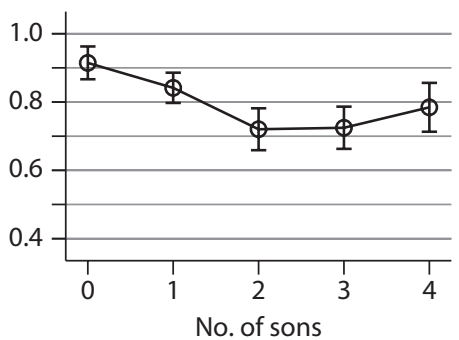

2012-2013

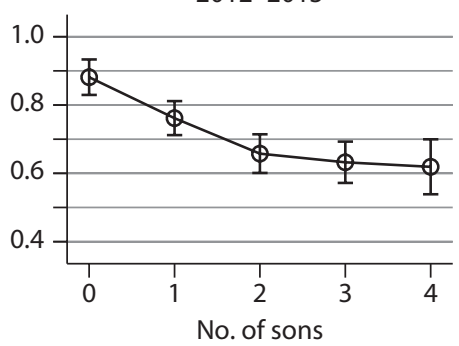

were about a quarter less likely to be using modern contraceptives than were those with only sons at both parity 1 ( $11 \%$ vs. $15 \%)$ and parity 2 (21\% vs. $29 \%$ ). At parity 3 , women without sons were half as likely to be using modern contraceptives as those with three sons (16\% vs. $31 \%$ ), and at parity 4 women without sons were nearly three-fourths less likely than those with four sons to be using modern contraceptives (14\% vs. 51\%). Overall, according to the Arnold method, the prevalence of modern contraceptive use among parous women would have been 19\% higher in 2012-2013 in the absence of son preference, equivalent to an increase to $36 \%$ from the observed value of $30 \%$.

In earlier years, the relationship between number of sons already born and contraceptive use was slightly less consistent. In 1990-1991, contraceptive usage was highest among women with a more balanced sex composition of children, though the highest rates of contraceptive use (>10\%) were observed among women with at least two sons for parities 3 and 4 . In all three surveys, and at virtually every parity, the lowest rates of contraceptive use were observed among women with no sons.
Figure 3 shows predicted probabilities from multinomial logit models of women's using any form of contraceptive (modern temporary, permanent or traditional). In the earliest PDHS, the number of sons already born was not associated with contraceptive use. In 2006-2007, women were significantly more likely to be using contraceptives after their second or third birth if they had had at least two sons, though there was no association between number of sons and contraceptive use after the fourth or fifth birth. However, results from 2012-2013 indicate a strong relationship between number of sons born and contraceptive use among women with 2-5 children. After a woman's second or third child, her predicted probability of using a modern method was $42 \%$ if she had at least two sons, but only $28 \%$ if she had no sons ( $p<.001)$. After a fourth or fifth birth, a woman's predicted probability of using contraceptives was $45-52 \%$ if she had two or more sons, compared with $30 \%$ if she had no sons $(\mathrm{p}<.001)$. A preference for at least two sons is again evident, and having additional sons was not associated with increased contraceptive use.

The number of sons born was strongly associated with use of permanent methods, especially after a woman's 


\begin{tabular}{|c|c|c|c|c|c|c|c|c|c|}
\hline \multirow{2}{*}{$\begin{array}{l}\text { Parity/sex } \\
\text { composition }\end{array}$} & \multicolumn{3}{|c|}{ 1990-1991 } & \multicolumn{3}{|c|}{ 2006-2007 } & \multicolumn{3}{|c|}{ 2012-2013 } \\
\hline & $\mathrm{N}$ & $\begin{array}{l}\text { \% using } \\
\text { modern } \\
\text { method }\end{array}$ & $\begin{array}{l}\text { Predicted } \\
\% \text { increase } \\
\text { in modern } \\
\text { method use } \\
\text { that would } \\
\text { occur in } \\
\text { absence } \\
\text { of son } \\
\text { preference }\end{array}$ & $\mathrm{N}$ & $\begin{array}{l}\% \text { using } \\
\text { modern } \\
\text { method }\end{array}$ & $\begin{array}{l}\text { Predicted } \\
\% \text { increase } \\
\text { in modern } \\
\text { method use } \\
\text { that would } \\
\text { occur in } \\
\text { absence } \\
\text { of son } \\
\text { preference }\end{array}$ & $N$ & $\begin{array}{l}\text { \% using } \\
\text { modern } \\
\text { method }\end{array}$ & $\begin{array}{l}\text { Predicted } \\
\% \text { increase } \\
\text { in modern } \\
\text { method use } \\
\text { that would } \\
\text { occur in } \\
\text { absence } \\
\text { of son } \\
\text { preference }\end{array}$ \\
\hline $\mathrm{All}^{\dagger}$ & 3,772 & 10.2 & 44.3 & 6,095 & 25.3 & 11.7 & 8,684 & 30.4 & 18.8 \\
\hline \multicolumn{10}{|l|}{ Parity 1} \\
\hline 0 boys, 1 girl & 351 & 1.7 & 76.2 & 521 & 8.2 & 9.6 & 803 & 10.6 & 40.7 \\
\hline 1 boy, 0 girls & 410 & 3.0 & na & 657 & 9.0 & na & 900 & 14.9 & na \\
\hline \multicolumn{10}{|l|}{ Parity 2} \\
\hline 0 boys, 2 girls & 163 & 6.6 & 44.9 & 285 & 11.0 & 104.4 & 398 & 21.3 & 37.4 \\
\hline 1 boy, 1 girl & 370 & 9.5 & na & 662 & 19.9 & 13.2 & 998 & 26.1 & 11.9 \\
\hline 2 boys, 0 girls & 228 & 7.9 & 21.0 & 359 & 22.5 & na & 530 & 29.2 & na \\
\hline \multicolumn{10}{|l|}{ Parity 3} \\
\hline 0 boys, 3 girls & 105 & 2.3 & 391.1 & 112 & 18.9 & 44.5 & 172 & 16.2 & 110.7 \\
\hline 1 boy, 2 girls & 286 & 8.4 & 37.7 & 404 & 26.2 & 4.1 & 614 & 31.1 & 9.6 \\
\hline 2 boys, 1 girl & 340 & 11.5 & na & 550 & 25.6 & 6.6 & 888 & 34.1 & na \\
\hline 3 boys, 0 girls & 114 & 7.0 & 63.9 & 201 & 27.3 & na & 244 & 30.7 & 11.3 \\
\hline \multicolumn{10}{|l|}{ Parity 4} \\
\hline 0 boys, 4 girls & 29 & 4.1 & 286.0 & 50 & 27.9 & 32.9 & 96 & 14.0 & 263.6 \\
\hline 1 boy, 3 girls & 182 & 12.9 & 21.7 & 245 & 20.6 & 80.6 & 366 & 33.3 & 52.6 \\
\hline 2 boys, 2 girls & 306 & 14.9 & 6.0 & 515 & 37.1 & 0.1 & 694 & 38.9 & 30.4 \\
\hline 3 boys, 1 girl & 189 & 15.8 & na & 349 & 37.1 & na & 461 & 42.5 & 19.5 \\
\hline 4 boys, 0 girls & 49 & 13.1 & 19.9 & 86 & 27.6 & 34.5 & 145 & 50.8 & na \\
\hline
\end{tabular}

FIGURE 3. Predicted probabilities (and 95\% confidence intervals) from logistic regression analyses examining the likelihood that women aged 15-49 would use a contraceptive method, by parity and number of sons, according to survey year, Pakistan Demographic and Health Survey

Predicted probability of using a contraceptive method after a second or third birth

1990-1991

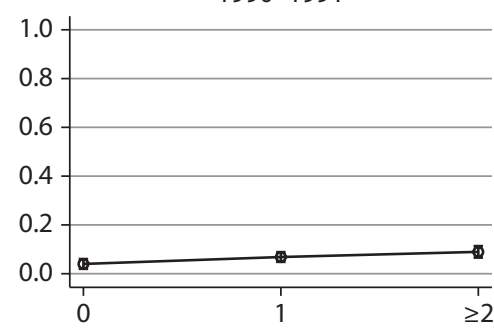

No. of sons
2006-2007

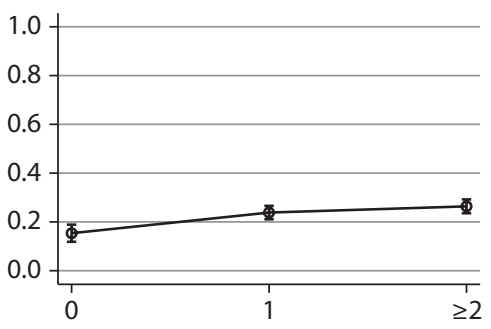

No. of sons
2012-2013

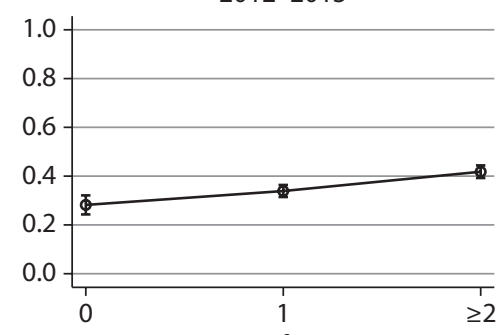

No. of sons

Predicted probability of using a contraceptive method after a fourth or fifth birth

1990-1991

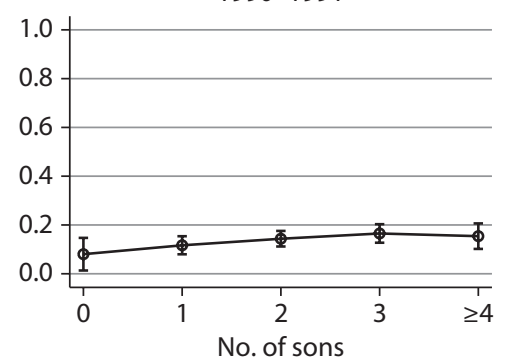

No. of sons
2006-2007

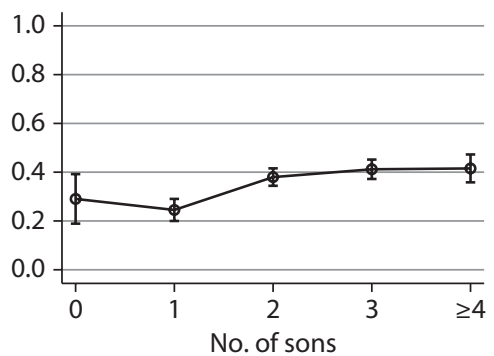

No. of sons
2012-2013

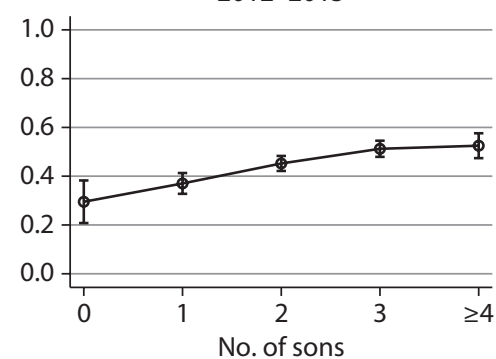


FIGURE 4. Predicted probabilities (and 95\% confidence intervals) from logistic regression analyses examining the likelihood that women aged 15-49 would use a permanent modern contraceptive method, by parity and number of sons, according to survey year, Pakistan Demographic and Health Survey

Predicted probability of using a permanent method after second or third birth

2006-2007

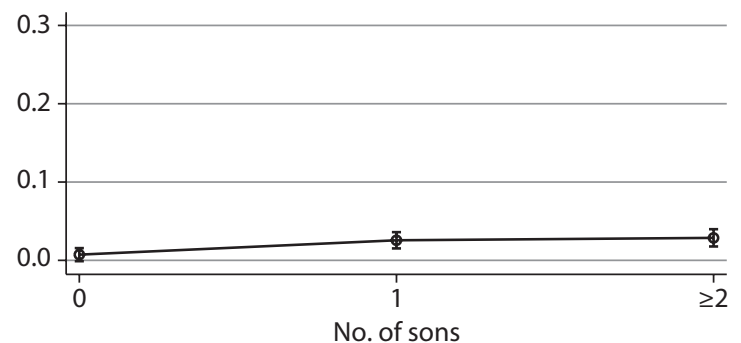

2012-2013

Predicted probability of using a permanent method after fourth or fifth birth

2006-2007

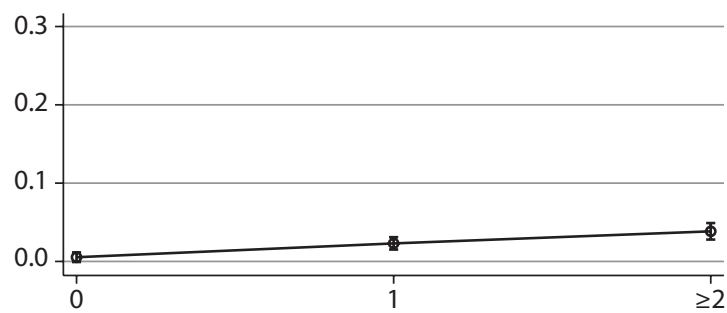

No. of sons

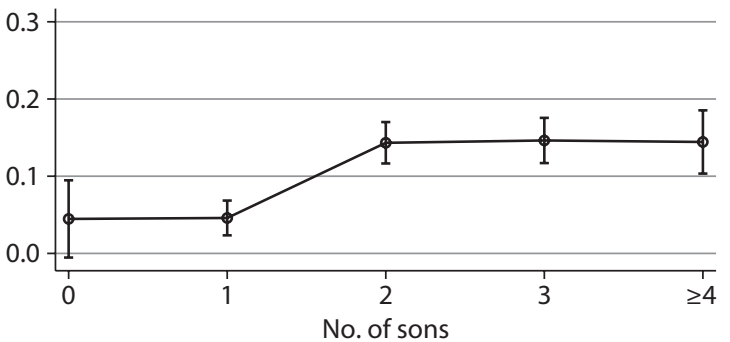

2012-2013

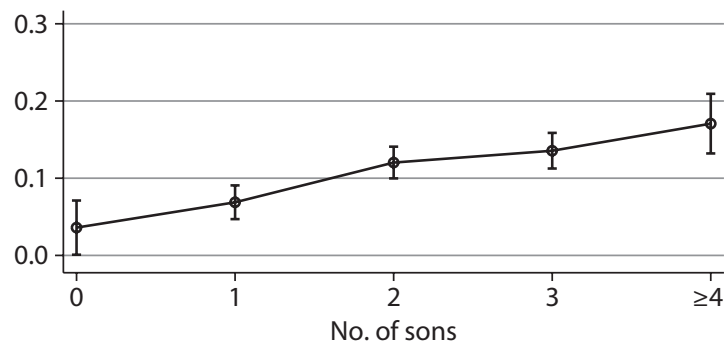

FIGURE 5. Predicted probabilities (and 95\% confidence intervals) from logistic regression analyses examining the likelihood that women aged 15-49 would use a temporary modern contraceptive method, by parity and number of sons, according to survey year, Pakistan Demographic and Health Survey

Predicted probability of using a temporary method after second or third birth

1990-1991

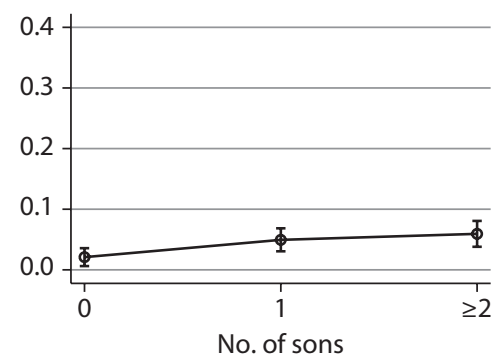

2006-2007

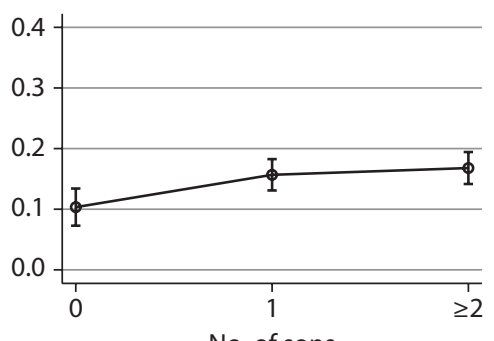

No. of sons
2012-2013

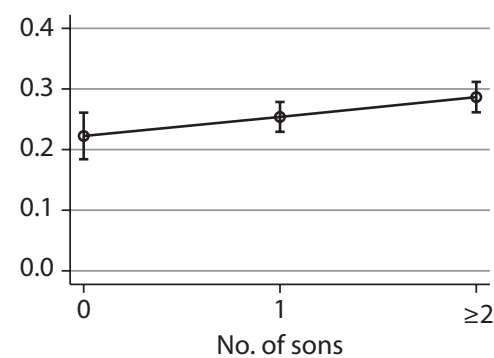

1990-1991

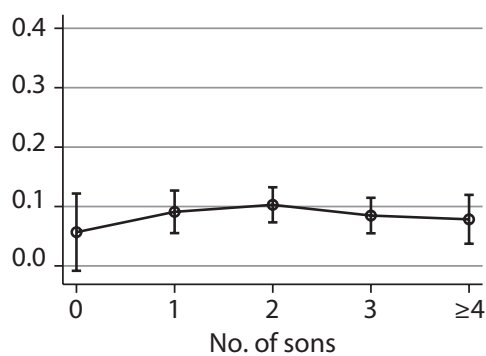

2006-2007

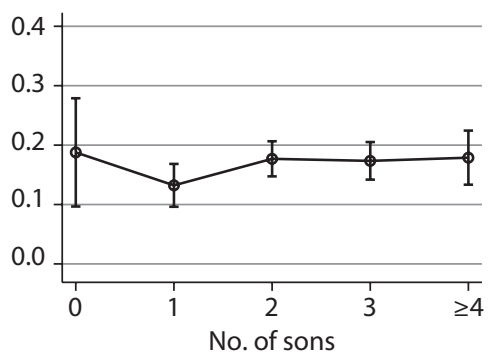

2012-2013

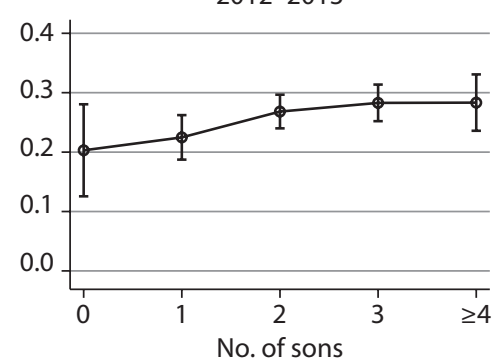

fourth or fifth birth (Figure 4). Once again, having two sons was key. For women with four or five children, the predicted probability of permanent method use in the 2012-2013 PDHS was just 4\% for those who had no sons, but it was $12 \%$ for women with two sons and $17 \%$ for those with four or more sons $(\mathrm{p}<.001)$. The probability did not differ between those with two sons and those with more than two sons. A similar pattern was evident in 2006-2007; results for 1990-1991 are not shown because use of permanent methods was extremely low and no significant differences were apparent.

In all three surveys, number of sons was associated with use of temporary modern methods among women with two or three children, and the strength of the 
association increased over time (Figure 5). For women with four or five children, the association was significant only in 2012-2013. No associations were observed for traditional method use (not shown), apart from a slight increase in 2006-2007 among women with three sons at parity 4 or $5(\mathrm{p}<.05)$.

\section{DISCUSSION}

This study shows that son preference has been established in Pakistan for at least two decades and is increasingly associated with contraceptive use and parity progression ratios through the practice of differential stopping behavior. Eliminating son preference would, in theory, result in increased contraceptive use and reduced fertilityoutcomes that are key targets of the Sustainable Development Goals-although the strong preference for four children might hold even in the absence of a preference for a specific sex composition. Indeed, the analyses suggest that son preference was a major contributor to Pakistan missing its MDG targets by a wide margin. It should also be noted that the findings within this paper suggest that son preference may continue to have a substantial effect on population growth through its inflationary effect on fertility. Because Pakistan's population, already the sixth largest on the planet, is projected to increase by about $70 \%$ by 2050 , the search for factors affecting its growth rate is urgent. If fertility falls without a similar decline in son preference, the result will be an intensification of the need to bear sons at a lower parity. ${ }^{22}$ The question of what will happen in the event that fertility falls further while son preference remains strong is an important one for both overall gender equality and sexual and reproductive health. That said, mean ideal family size remains above four children and has not decreased since 1990-1991. Thus, many women and men in Pakistan do not yet face the pressure of the low ideal family sizes that have resulted in the intensification of son-preferring behaviors in nearby India and Nepal. Areas where fertility decline is accelerating (such as the Islamabad Capital Territory) should be monitored and may provide a preview of the likely future trajectory of the country as a whole.

In other South Asian countries, such as India and Nepal, a culture of strong son preference combined with falling fertility has resulted in prenatal sex selection. ${ }^{1,11-13}$ Pakistan's abortion laws are much more restrictive than those in India and Nepal (notwithstanding the fact that sex selection itself is illegal in those two countries). To date, no solid evidence exists that sex-selective abortions are occurring in Pakistan, but such abortions could become prevalent in a climate of falling fertility, especially among individuals who are better educated, are relatively wealthy and live in urban areas. ${ }^{29}$ In Nepal, sex ratios at birth became skewed only when the national total fertility rate declined to roughly 3.1. The cultural context is different in Pakistan (particularly in that the population is mostly Muslim), which may mean that differential stopping behavior will continue to be the primary means for realizing son preference. In the event that differential stopping behavior continues on a large scale, Pakistan may well see a stall in its nascent fertility transition and struggle to increase the prevalence of contraceptive use.

Some researchers have proposed that countries where son preference is strong experience a sex ratio transition characterized by a steady increase in differential stopping behavior (evidenced by an increasing sex ratio at last birth) followed by an increase in prenatal sex selection (evidenced by an increasingly skewed sex ratio at birth) and finally a normalization of both the sex ratio at last birth and the overall sex ratio at birth. ${ }^{1,4,40}$ Such a transition would be expected to occur alongside the fertility transition, though whether the fertility transition drives the sex ratio transition or vice versa is not clear. Both transitions could stall in Pakistan, because ideal family size remains high (higher than actual fertility) and sex-selective abortions do not appear to be occurring. Alternatively, with the right interventions to reduce gender inequality and empower women and girls, is it possible that Pakistan will continue on its path of fertility transition and achieve a normal sex ratio at last birth without ever experiencing the skewed sex ratios at birth seen in other countries? If Pakistan were to take this second route, it would be a significant success and provide a notable learning opportunity for other countries with high levels of both fertility and son preference, such as Afghanistan and Mauritania.

This study examined the relationship between son preference and contraception using different categories of contraceptive methods (permanent, temporary and traditional) rather than a dichotomous approach of use versus nonuse. The findings suggest that the association between the sex composition of children and contraceptive use is stronger for permanent methods than for temporary ones. In all three surveys, use of permanent methods was virtually nonexistent among women who had no sons, but by 2012-2013 women had a significantly elevated likelihood of using a permanent method if they had sons, and especially if they had at least two sons. The decision to use a permanent method is likely based on a combination of family size preferences and son preferences, as seems to be the case in India, ${ }^{41}$ though ideal family size is much more of a constraint in that country than in Pakistan. Sex composition is also beginning to be associated with temporary method use, though without longitudinal data it is not possible to see if use of temporary methods and use of permanent methods differ depending on the stage of a woman's reproductive life course and the sex composition of her children

This study looked at both reported and revealed son preference-that is, both stated desires and the association between sex composition of children and subsequent reproductive behavior. While it is important to collect information on sex preferences directly, such data do not necessarily give us an accurate representation of the extent to which son preference may 
be affecting reproductive behavior. A previous analysis found a decline in the desired sex ratio at birth occurring at the same time as increases in measures of realized son preference (such as the sex ratio at last birth or the sex ratio at birth). ${ }^{4}$ Indeed, this study found that the desired sex ratio at birth has fallen substantially since 19901991 and that Pakistanis increasingly appear to be making reproductive decisions on the basis of the number of sons they have. Further, while both men and women commonly say that they want a balanced sex composition, with a preference for two sons and two daughters, the data suggest that the preference for a minimum of two sons trumps the preference for two daughters. This can be seen especially in the association between number of sons and use of permanent methods.

Interpretation of the present results calls for caution. Given that the family composition data were self-reported, the main concern is the under- or misreporting of female births, a well-known phenomenon in Pakistan and other South Asian countries. ${ }^{29,42}$ Women tend to underreport children who died (who may be disproportionately female in a climate of son preference) and those who have left home. The parity-specific nature of the analyses mitigates this issue to some extent, since it is unlikely that reporting errors would result in such a clear relationship between number of sons and both parity progression and contraceptive method use. Another limitation is the necessary exclusion of non-numeric preference data, though this does not affect the analyses of parity progression and contraceptive use.

The current findings suggest that son preference has a substantial demographic impact in Pakistan and has been a major contributory factor in Pakistan's failing to achieve some of the MDGs. It is imperative that son preference be addressed if Pakistan is going to complete the fertility transition and significantly improve its citizens' reproductive health, while avoiding the sex ratio imbalances seen in other countries in South Asia. Addressing these issues, moreover, is essential to the country's management of population growth.

\section{REFERENCES}

1. Guilmoto CZ, The sex ratio transition in Asia, Population and Development Review, 2009, 35(3):519-549.

2. Jejeebhoy SJ and Sathar ZA, Women's autonomy in India and Pakistan: the influence of religion and region, Population and Development Review, 2001, 27(4):687-712.

3. Channon MD, Son preference, parity progression and contraceptive use in South Asia, Population Horizons, 2015 , 12(1):24-36.

4. Bongaarts J, The implementation of preferences for male offspring, Population and Development Review, 2013, 39(2):185-208

5. Jayaraman A, Mishra V and Arnold F, The relationship of family size and composition to fertility desires, contraceptive adoption and method choice in South Asia, International Perspectives on Sexual and Reproductive Health, 2009, 35(1):29-38.

6. Chaudhuri S, The desire for sons and excess fertility: a householdlevel analysis of parity progression in India, International Perspectives on Sexual and Reproductive Health, 2012, 38(4):178-186.
7. Zaidi B and Morgan SP, In the pursuit of sons: additional births or sex-selective abortion in Pakistan? Population and Development Review, 2016, 42(4):693-710.

8. Hunte PA and Sultana F, Health-seeking behavior and the meaning of medications in Balochistan, Pakistan, Social Science $\mathbb{E}$ Medicine, 1992, 34(12):1385-1397.

9. Pebley AR and Amin S, The impact of a public-health intervention on sex differentials in childhood mortality in rural Punjab, India, Health Transition Review, 1991, 1(2):143-169.

10. Hazarika G, Gender differences in children's nutrition and access to health care in Pakistan, Journal of Development Studies, 2010, 37(1):73-92.

11. Fledderjohann J et al., Do girls have a nutritional disadvantage compared with boys? Breastfeeding, food consumption, and mortality among Indian siblings, European Journal of Public Health, 2014, 24(Suppl. 2): cku162-060, doi: 10.1093/eurpub/ckul62.060.

12. Miller BD, Female infanticide and child neglect in rural North India, in: Scheper-Hughes, ed., Child Survival, Dordrecht, Holland: D. Reidel Publishing, 1987, pp. 95-112.

13. Sudha $S$ and Irudaya RS, Female demographic disadvantage in India 1981-1991: sex selective abortions and female infanticide, Development and Change, 1999, 30(3):585-618.

14. Jha P et al., Trends in selective abortions of girls in India: analysis of nationally representative birth histories from 1990 to 2005 and census data from 1991 to 2011, Lancet, 2011, 377(9781):1921-1928.

15. Frost MD, Puri M and Hinde PRA, Falling sex ratios and emerging evidence of sex-selective abortion in Nepal: evidence from nationally representative survey data, BMJ Open, 2013, 3(5):e002612, doi: 10.1136/bmjopen-2013-002612.

16. Zhu WX, Lu L and Hesketh T, China's excess males, sex selective abortion, and one child policy: analysis of data from 2005 national intercensus survey, BMJ, 2009, 338:b1211, doi: 10.1136 bmj.bl21l.

17. Sen A, Missing women, BMJ, 1992, 304(6827):587-588.

18. National Institute of Population Studies (NIPS) and ICF International, Pakistan Demographic and Health Survey 2012-13, Islamabad, Pakistan: NIPS; and Calverton, MD, USA: ICF International, 2013, https://dhsprogram.com/pubs/pdf/fr290/ fr290.pdf

19. Kashyap R, The dynamics of prenatal sex selection and excess female child mortality in contexts with son preference, unpublished dissertation, Oxford, UK: University of Oxford, 2017.

20. Edmeades J et al., Two sons and a daughter: sex composition and women's reproductive behaviour in Madhya Pradesh, India, Journal of Biosocial Science, 2012, 44(6):749-764.

21. Calhoun LM et al., The effect of family sex composition on fertility desires and family planning behaviors in urban Uttar Pradesh, India, Reproductive Health, 2013, 10(1):48, doi: 10.1186/1742-4755-10-48

22. Bhat PN and Zavier AJ, Fertility decline and gender bias in northern India, Demography, 2003, 40(4):637-657.

23. Basu D and de Jong R, Son targeting fertility behavior: some consequences and determinants, Demography, 2010, 47(2):521-536

24. Planning Commission, Government of Pakistan, Pakistan Millennium Development Goals Report 2013, Islamabad, Pakistan: Ministry of Planning, Development and Reform, 2013, http:// www.pk.undp.org/content/dam/pakistan/docs/MDGs/ MDG2013Report/final\%20report.pdf.

25. Jain AK et al., Reducing unmet need and unwanted childbearing evidence from a panel survey in Pakistan, Studies in Family Planning, 2014, 45(2):277-299.

26. Population Division, United Nations Department of Economic and Social Affairs, World Population Prospects: The 2015 Revision, Geneva: United Nations, 2015. 
27. Pakistan Penal Code, Act XLV of 1860, Chapter XVI, Section 338(A)-(C).

28. Sathar $Z$ et al., Induced abortions and unintended pregnancies in Pakistan, Studies in Family Planning, 2014, 45(4):471-491.

29. Sathar ZA et al., Evidence of Son Preference and Resulting Demographic and Health Outcomes in Pakistan, Islamabad, Pakistan: Population Council, 2015, https://www.popcouncil.org/uploads/ pdfs/2015PGY_SexSelectionPakistan.pdf.

30. Sathar ZA, Singh S and Fikree FF, Estimating the incidence of abortion in Pakistan, Studies in Family Planning, 2007, 38(1):11-22.

31. Shi Y and Kennedy JJ, Delayed registration and identifying the "missing girls" in China, China Quarterly, 2016, 228:1018-1038, doi: $10.1017 /$ S0305741016001132.

32. NIPS and Macro International, Pakistan Demographic and Health Survey 2006-07, Islamabad, Pakistan: NIPS and Macro International, 2008, https://dhsprogram.com/pubs/pdf/FR200/FR200.pdf.

33. NIPS and Institute for Resource Development (IRD)/Macro International, Pakistan Demographic and Health Survey 1990/1991 Islamabad, Pakistan: NIPS; and Columbia, MD, USA: IRD/Macro International, 1992, https://dhsprogram.com/pubs/pdf/FR29/ FR29.pdf.

34. Arnold F, Measuring the effect of sex preference on fertility: the case of Korea, Demography, 1985, 22(2):280-288.

35. Retherford RD and Choe MK, Statistical Models for Causal Analysis, New York: John Wiley \& Sons, 2011

36. Magadi MA and Curtis SL, Trends and determinants of contraceptive method choice in Kenya, Studies in Family Planning, 2003, 34(3):149-159.

37. Coale AJ, The demographic transition reconsidered, in: International Union for the Scientific Study of Population (IUSSP), Proceedings of the International Population Conference, Vol. 1, Liège, Belgium: IUSSP, 1973, pp. 53-72.

38. Frye $\mathrm{M}$ and Bachan L, The demography of words: the global decline in non-numeric fertility preferences, 1993-2011, Population Studies, 2017, 71(2):187-209.

39. Dahal GP, Padmadas SS and Hinde PR, Fertility-limiting behavior and contraceptive choice among men in Nepal, International Family Planning Perspectives, 2008, 34(1):6-14.

40. Guilmoto CZ, The masculinization of births. Overview and current knowledge, Population, 2015, 70(2):183-243.

41. Edmeades J et al., Son preference and sterilisation use among young married women in two slums in Bengaluru city, India, Global Public Health, 2011, 6(4):407-420.

42. Clark S, Son preference and sex composition of children: evidence from India, Demography, 2000, 37(1):95-108.

\section{RESUMEN}

Contexto: La preferencia por hijos varones ejerce una fuerte influencia sobre las decisiones en materia de anticoncepción y fecundidad en muchos países del Sur de Asia. En Pakistán, en donde la fecundidad permanece alta y el uso de anticonceptivos bajo, las investigaciones en torno a esta preferencia han sido limitadas.

Métodos: Se usaron datos de las Encuestas Demográficas y de Salud de Pakistán conducidas en 1990-1991, 2006-2007 y 2012-2013 para examinar indicadores potenciales y resultados relativos a la preferencia por hijos varones. Los análisis descriptivos observaron las preferencias de hombres y mujeres en la composición del sexo, así como la razón del sexo del último nacimiento. Se examinó la progresión de paridad por orden de nacimiento a través de análisis de regresión logística multivariada, mientras que se usó regresión logística multinomial para identificar las asociaciones entre la composición del sexo y el uso de métodos anticonceptivos permanentes, temporales y tradicionales.

Resultados: La progresión de paridad y la elección del método anticonceptivo están cada vez más asociadas con la composición del sexo de los hijos. Muchas personas entrevistadas deseaban al menos dos hijos varones, aunque la mayoría también deseaba al menos una hija. Los análisis sugieren que la prevalencia del uso de métodos anticonceptivos modernos en mujeres que habían tenido hijos habría sido 19\% más alta en 2012-2013 en ausencia de la preferencia por hijos varones. El uso de métodos permanentes fue extremadamente bajo en mujeres sin hijos varones y aumentó significativamente con el aumento en el número de hijos varones. La asociación entre el número de hijos varones y el uso de métodos temporales fue débil, mientras que la preferencia por hijos varones tuvo poca relación con el uso de métodos tradicionales.

Conclusiones: La asociación de la preferencia por hijos varones con la progresión de paridad y el uso de anticonceptivos modernos se ha fortalecido en Pakistán. La continuación de la transición de la fecundidad puede ser difícil a menos que disminuyan los grados de conducta diferencial de suspensión y de uso diferencial de anticonceptivos.

\section{RÉSUMÉ}

Contexte: La préférence pour les garçons exerce une forte influence sur les décisions contraceptives et de fécondité dans de nombreux pays d'Asie du Sud. Au Pakistan, où la fécondité reste élevée et la pratique contraceptive, faible, la recherche sur cette préférence est limitée.

Méthodes: Les données des Enquêtes démographiques et de santé pakistanaises de 1990-1991, 2006-2007 et 2012-2013 ont servi à examiner les indicateurs potentiels et les résultats de la préférence accordée aux garçons. Les préférences de composition sexuée exprimées par les hommes et par les femmes sont étudiées par analyses descriptives, de même que le rapport de masculinité à la dernière naissance. L'agrandissement en fonction du rang de naissance est examiné par analyses de régression logistique multivariée, tandis que la régression logistique multinomiale sert à identifier les associations entre la composition sexuée et le recours aux méthodes contraceptives permanentes, temporaires et traditionnelles.

Résultats: L'agrandissement et le choix de méthode contraceptive sont de plus en plus associés à la composition sexuée de la descendance. Beaucoup de répondants désiraient avoir au moins deux garçons, mais, pour la plupart, au moins une fille aussi. Les analyses laissent entendre que la prévalence de la pratique contraceptive moderne parmi les femmes déjà mères aurait été de 19\% supérieure en 2012-2013 en l'absence de la préférence pour les garçons. Le recours aux méthodes permanentes est extrêmement faible parmi les femmes qui n'ont pas de garçons; il augmente significativement avec le nombre de garçons. L'association entre le nombre de garçons et la pratique des méthodes temporaires est plus faible, tandis que la préférence pour les garçons est pratiquement sans rapport avec celle des méthodes traditionnelles. 
Conclusions: L'association de la préférence pour les garçons avec l'agrandissement et la pratique contraceptive moderne est devenue plus forte au Pakistan. La continuation de la transition de la fécondité pourra être difficile si les degrés de comportement d'arrêt différentiel et de pratique contraceptive différentielle ne s'amoindrissent pas.

\section{Acknowledgments}

This work was undertaken as part of the Collen Programme, funded by Life Sciences Research Partners.

Author contact: melanie.channon@ageing.ox.ac.uk 
Reproduced with permission of copyright owner. Further reproduction prohibited without permission. 